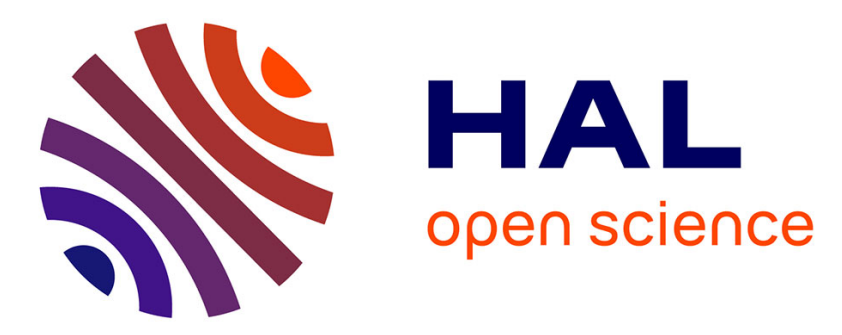

\title{
A Longitudinal Analysis of Trajectory Changes in the Software Industry: The Case of the Content Management Application Segment
}

\author{
Claudio Vitari, Aurelio Ravarini
}

\section{- To cite this version:}

Claudio Vitari, Aurelio Ravarini. A Longitudinal Analysis of Trajectory Changes in the Software Industry: The Case of the Content Management Application Segment. European Journal of Information Systems, 2009, 37 p. 10.1057/ejis.2009.13 . hal-00462408

\section{HAL Id: hal-00462408 http://hal.grenoble-em.com/hal-00462408}

Submitted on 10 Mar 2010

HAL is a multi-disciplinary open access archive for the deposit and dissemination of scientific research documents, whether they are published or not. The documents may come from teaching and research institutions in France or abroad, or from public or private research centers.
L'archive ouverte pluridisciplinaire HAL, est destinée au dépôt et à la diffusion de documents scientifiques de niveau recherche, publiés ou non, émanant des établissements d'enseignement et de recherche français ou étrangers, des laboratoires publics ou privés. 


\section{A Longitudinal Analysis of Trajectory Changes in the Software Industry: The Case of the Content Management Application Segment.}

Claudio Vitari1 and
Aurelio Ravarini2
1 Grenoble Ecole de Management, Grenoble, France
2Università Carlo Cattaneo, Castellanza, Italy
Correspondence:
C. Vitari,
Grenoble Ecole de Management
12, rue Pierre Sémard
BP 127
38003 Grenoble CEDEX 01
France
Tel: 0033476706287 ;
E-mail: claudio.vitari@grenoble-em.com

Claudio Vitari1 and

E-mail: claudio.vitari@grenoble-em.com

\begin{abstract}
The software industry is changing as a result of the rising influence both of packaged and of Free/Libre/Open Source Software (FLOSS), but the change trajectory of the industry is still not well understood. This article aims to contribute to clarifying software industry evolution through a longitudinal study, using Industry Change Trajectory Theory to explain and predict the evolution of the Content Management Systems (CMS) segment and the extent to which its results can be generalized to the overall software industry.

Our data analysis shows that CMS players are experiencing a modification of their segments' change trajectory. While McGahan in 2004 recognized that the software industry was in a creative change trajectory, it has subsequently faced strong competition on its core assets, (i.e. applications) and the empirical results of our longitudinal study from 2002 to 2007 show the CMS segment is now in a radical change trajectory, due to the rapid obsolescence of its core activities. The paper discusses the changes affecting the segment, and proposes extending the outcome of the study to other segments of the software industry.
\end{abstract}

Keywords: software industry; FLOSS software; packaged software content management systems; industry change trajectory. 


\section{The software industry changes trajectory: the case of Content Management System segment.}

\section{Introduction}

The software industry receives billions of dollars from the selective investments of its customers (Boonstra, 2003) which impacts its evolution trends. On the one hand, the typical dilemma between developing an Information System (IS) internally or finding it elsewhere increasingly favours the latter option, with the result that the currently available 'off-the-shelf' software applications are gaining substantial ground in the market (Pang, 2008; Sawyer, 2000; Leebaert, 1995; Price Waterhouse, 1998; Quintas, 1994; Voas, 1998; Voas, 2001; ReportSURE, 2005; Succi et al., 2001; Paulson et al., 2004; Adam \& Light, 2004). On the other hand, Free/Libre/Open Source Software (FLOSS) is becoming an ever-more significant reality in many different software industry segments (Driver et al., 2008; Succi et al., 2001; Fitzgerald, 2006; Economides \& Katsamakas, 2006; Gutsche, 2005; Bell et al., 2007).

Despite the evident importance of these two underlying trends, change in the software industry seems to have been insufficiently explored in academic literature (Fitzgerald, 2006; McGahan, 2004b), and more specifically, longitudinal studies of the trajectory of software industry evolution are lacking. We have conducted a longitudinal study, based on McGahan's Industry Change Trajectory Theory, on the evolution of one specific software industry segment - Content Management Systems (CMS) - paying particular attention to the differences between packaged and FLOSS CMS. We chose the CMS segment because it is a dynamic market that has grown significantly over just a few years.

Our research thus contributes to explaining and predicting change in the Content Management Systems segment and (through the generalization of our findings) in the software industry as a whole. The paper begins by giving the theoretical and empirical background to our research. Our research approach is then described, and our results presented and considerations about the segment's change trajectory discussed. Finally, conclusions are drawn and avenues for further research are outlined.

\section{Theoretical and empirical background}

\section{Definitions}

A clear definition of the research topic is necessary to contextualize our research issues, although defining the subject can often be a challenge in the software arena. While the name Content Management Systems is commonly used for commercial purposes, it has no generally recognized definition, so the market offers products 
under that label that differ significantly, while at the same time software systems with many similar functionalities are commercialized under other labels such as DMS (Document Management Systems) and KMS (Knowledge Management Systems). The following paragraphs provide definitions - substantiated by our literature review - of the key terms in our research area.

Content (defined in general as something that is contained, as in a receptacle (Pickett, 2000)) can embrace a wide range of types of information, from simple ASCII-format texts to multimedia objects (AIIM, 2002), regardless of how and where they are published. In our research context, the label refers to the information contained in web sites. Thus, in our context, Content Management (CM) - which has been generally defined as the process of capturing, codifying, storing and sharing information that is vital to an organization (Bradley et al., 2006) - relates to the management of web site content, while a Content Management System (CMS) has been defined as 'a software application that allows the creation, collection, management, publication and modification of the content of web sites.' (AIIM, 2002). Packaged Software is commercially available software, where the user has no free access to the source code and no rights to redistribute. It is typically licensed onto the mass market as a tradable, ready-made, off-the-shelf, pre-built product, whose eventual customization is controlled by the vendor. Thus Packaged CMS refers to commercially produced software packages supporting the management of web site content. Free/Libre/Open Source Software (FLOSS) is software the user can use for any purpose, study its source code, adapt it to his needs, and redistribute - modified or unmodified (Free Software Foundation, 2007), and FLOSS CMS is thus CMS application software derived from this type of source.

\section{The Content Management System segment}

The CMS industry is very young, with the first software only being released in 1998 (Pelz-Sharpe et al., 2002). In industry life-cycle terms (Frankl \& Rubik, 2000), its introduction period can be considered as having been completed by 2000 (Pelz-Sharpe et al., 2002). Market research (Wintergreen Research, 2005) estimated a sharp increase in the CMS industry's total revenue over the next few years: from an estimated worldwide size in 2006 of $\$ 3.6$ billion, the CMS market is expected to reach $\$ 4.2$ billion by 2010 . However, software market growth also depends on the proportion of potential customers that develop their own original CMS internally, and Frost and Sullivan have estimated that $70 \%$ of them had already done so (Comtex, 2002). Although the CMS industry has been dominated by the customized development of Information Systems, both packaged and FLOSS-based software developments have also increased. At the same time, the CMS industry is expanding and CMS applications are extending their functions and advancing technologically, as is the whole software industry. 


\section{The change trajectory of the CMS segment}

Although the introduction period of the CMS segment has passed (Pelz-Sharpe et al., 2002), it is difficult to define precisely which change trajectory the CMS segment is undergoing and where it actually stands in its life cycle (Frankl \& Rubik, 2000). Industry Change Trajectory Theory (McGahan, 2004b) allows us to understand better than previous models (e.g. industry life cycle model) (McGahan et al., 2004) the different possible industry life cycle stages and their change trajectories, and has been used to better understand firms' evolutions and their industry-related risks (Konana \& Ray, 2007; Melville et al., 2005; Melville et al., 2007). The theory also has normative objectives, in proposing a set of strategic actions to apply to the identified industry trajectory.

McGahan's Industry Change Trajectory Theory (McGahan, 2004b) proposes 4 main trajectories of industry change: radical, progressive, creative, and intermediating as 'trajectories [that] set the boundaries on what will generate profits in a business' (page 88). Industries can be threatened by two types of obsolescence: obsolescence of core activities (the recurring actions that create value by making suppliers more willing to transact and buyers more willing to pay) and/or obsolescence of core assets (the durable resources, including intangibles, that make the organization more efficient or effective at performing its core activities) (see Table 1).

\begin{tabular}{|c|c|c|}
\hline $\begin{array}{c}\text { Threats of } \\
\text { obsolescence }\end{array}$ & Core activities threatened & Core activities unthreatened \\
\hline $\begin{array}{l}\text { Core assets } \\
\text { threatened }\end{array}$ & $\begin{array}{l}\text { Radical change } \\
\text { Examples: overnight letter delivery, landline telephone } \\
\text { manufacturing, typewriter manufacturing } \\
\text { Rules of change include: } \\
\text { - Carefully identifying profitable activities and scaling back } \\
\text { unprofitable activities } \\
\text { - Avoiding the commitment of long-lived assets into the } \\
\text { business } \\
\text { Opportunities for innovation involve: } \\
\text { - Assessing the timing of change accurately and retaining a } \\
\text { profitable position as long as possible } \\
\text { - Developing efficiencies by replacing fixed assets with variable } \\
\text { activities }\end{array}$ & $\begin{array}{l}\text { Creative change } \\
\text { Examples: Pharmaceuticals, motion-picture production, oil } \\
\text { and gas exploration } \\
\text { Rules of change include: } \\
\text { - Committing resources to high-potential projects without } \\
\text { reliable market information } \\
\text { - Developing a system for bringing successful projects to } \\
\text { market } \\
\text { - Abandoning failing projects } \\
\text { Opportunities for innovation involve: } \\
\text { - Creating breakthrough asset-development projects } \\
\text { - Developing efficient and effective systems for delivering } \\
\text { projects to market }\end{array}$ \\
\hline $\begin{array}{l}\text { Core assets } \\
\text { unthreatened }\end{array}$ & $\begin{array}{l}\text { Intermediating change } \\
\text { Examples: Investment brokerage, fine-arts auctions, automobile } \\
\text { dealerships } \\
\text { Rules of change include: } \\
\text { - Adapting to new ways of transacting with customers and } \\
\text { suppliers } \\
\text { - Scaling back commitments to fixed infrastructure } \\
\text { - Finding ways to redeploy assets out of the business into more } \\
\text { profitable uses } \\
\text { Opportunities for innovation involve: } \\
\text { - Focusing early on a core group of loyal customers } \\
\text { - Engaging in partnerships and alliances with rivals, customers, } \\
\text { or suppliers } \\
\text { - Forward or backward integrating into a customer's or } \\
\text { supplier's business }\end{array}$ & $\begin{array}{l}\text { Progressive change } \\
\text { Examples: discount retailing, long-haul trucking, commercial } \\
\text { airlines } \\
\text { Rules of change include: } \\
\text { - Constant market testing before full-scale commitment } \\
\text { - Competitive benchmarking and openness about } \\
\text { accomplishments } \\
\text { - Building capabilities incrementally over time rather than } \\
\text { through the acquisition of assets } \\
\text { Opportunities for innovation involve: } \\
\text { - Building a system that dominates a geographic or product } \\
\text { - Tightly linking activities }\end{array}$ \\
\hline
\end{tabular}

Table 1 The four industry change trajectories from McGahan (2004a: 9)

Radical change, which is relatively infrequent, occurs when core activities and core assets both suffer the threat of obsolescence at the same time. When this happens, the industry may change completely, although 
because the erosion of assets and activities is gradual such change might take time. During this period, organizations can still remain profitable if they manage this gradual change intelligently, and develop certain strategic and emerging lines of business to cope with the situation as and when the change reaches maturity.

Intermediating change is very frequent and occurs when core activities are threatened by obsolescence, but core assets are preserved and hence are available to (and must) be deployed differently. The first risk in this situation is that management under-estimates the threat of obsolescence, but even if the risk is assessed appropriately, managing intermediating change remains very difficult, since new ways of employing preserved core assets and building new core activities must be found, so that both suppliers and buyers can be retained. This process often results in a new business (or even a new industry) being developed.

Creative change, the least frequent change, occurs when core assets are threatened by obsolescence but core activities preserve their value. In this situation, the obsolescence of core assets rapidly reduces their value, and companies must respond quickly and constantly to develop valuable new core assets to replace them. But relationships with buyers and suppliers will maintain their value, so companies will aim to capitalize on them. In this situation, the risk lies in firms focusing exclusively on developing initiatives to renew their core assets, and neglecting to simultaneously continue to cultivating their core activities.

Progressive change is most frequent type: neither core assets nor core activities are threatened by obsolescence, and this trajectory is therefore the most stable, since change takes place within the existing business framework where relationships with buyers and suppliers are preserved and resources remain durable. Nevertheless, this change trajectory can have a deep impact on the relative competitive positions of different companies in the same market: those that perceive progressive change accurately will move to differentiate their market offers from those of their competitors through the incremental development of distinguishing resources and relationships.

In terms of the software industry specifically, different studies show that the industry is constantly redeveloping its assets (McGahan, 2004b; Izushi \& Aoyama, 2006) which are represented mainly by software applications and their supporting hardware (McGahan, 2004b). But as core software industry activities are not considered threatened by rapid obsolescence, the software industry appears to be following a creative change trajectory. However, more recent studies have revealed some software industry changes that may impact its change trajectory. A shift toward commoditization (Carr, 2003) and service economy is taking place in the IS field - "The growth in services is also fuelled by firms using it as a defence against the commoditization of goods' (Rai \& Sambamurthy, 2006). Another emerging trend is represented by the growth of FLOSS projects, 
which impact on software companies' revenues and thus on their commercial policies (Fitzgerald, 2006; West, 2003).

On this basis, this paper discusses Industry Change Trajectory Theory (McGahan, 2004b) and informs McGahan's theory's findings about the trajectory of the specific CMS segment of the software industry. This segment was chosen for study for two reasons. Firstly, the CMS market is growing fast, and the speed of its growth stimulates developers to release frequent new versions of their applications (Basili \& Boehm, 2001; Latham, 2007b). Secondly, the CMS market is relatively open and its growth attracts new actors (Latham, 2007a), whose entrance results in faster change than in other software industry segments. Frequent new releases and the advent of new entrants both threaten existing CMS developers, accelerating the pace of obsolescence, and obliging CMS developers in turn to constantly redevelop their applications (their core assets) to protect their customer relationships and remain competitive (Wallnau, 1999).

It is questionable whether this evolution affects the core activities (software development, engineering, selling, etc.) of CMS organizations. Following the indications of McGahan's change trajectory taxonomy about the software industry as a whole, the CMS segment seems at first sight following a creative change trajectory. Based on this model, our research attempts to examine the segment's change trajectory through a detailed longitudinal study of a set of CMS applications.

\section{Research approach}

This paper adopts a positivist approach in applying Industry Change Trajectory Theory (McGahan, 2004b) to explore the trajectory of change in the CMS segment and predict future developments. The data collected help inform the Industry Change Trajectory Theory and we discuss the degree to which our results can be generalized and applied to the whole Software Industry. Our longitudinal study is first introduced, and the different time phases and associated actions explained. We then use Porter's strategic grouping as a research approach to explore the differences and evolution of CMS applications. We next describe the strategic variables used to group the CMS applications: the number of functions available to users, the costs to users and the number of services offered. Finally, we explain the criteria applied to selecting CMS, and in collecting and analysing the data.

The first step of the study consisted of identifying the most suitable research method to examine the evolution of CMS applications over time. The research was conducted through a 5 year longitudinal study 
involving three empirical phases: Phase 1 in May 2002, Phase 2 in November 2004 and Phase 3 in September 2007. Three actions were performed at each phase (see Figure 1):

1. CMS selection: the set of CMS applications was selected;

2. Data collection: empirical up-to-date data was collected for each CMS application of the selected set and for each strategic variable;

3. Data analysis: collected data was analysed to identify the trajectory of change in the CMS segment.

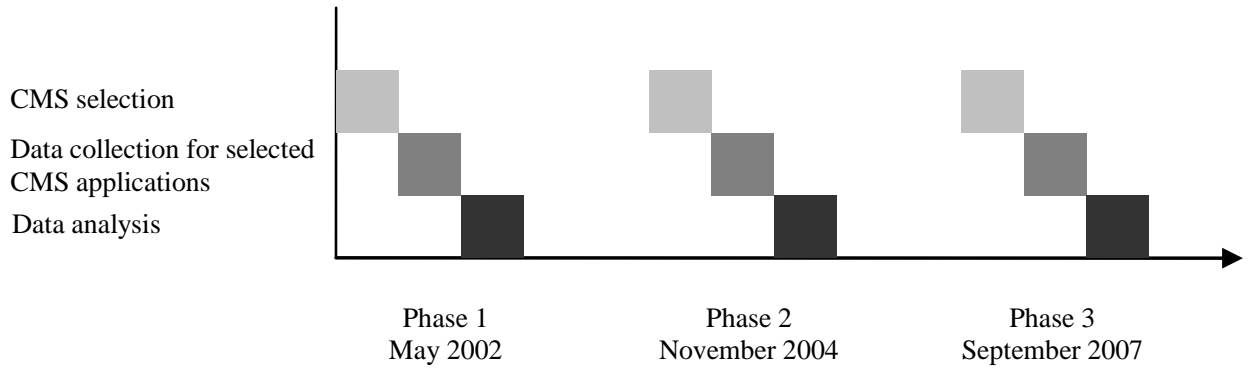

Figure 1 The timeline and main activities of the longitudinal study

After reviewing the analysis tools for the IT market (Usoro, 2001; Levy \& Powell, 2000; Pollock \& Williams, 2008; Porter, 1980), we based our research on Porter's strategic grouping approach (Porter, 1980), which identifies the differences between units of analysis using the most strategic variables. In our case, the units of analysis were the CMS applications, and we identified and measured the most strategic variables at each of the three temporal phases. Using only the most strategic variables makes this approach relatively simple and allows for quicker data collection. However, this simplicity can also be seen as limitation, in that the method can only partially represent the complexity of the segment. Notwithstanding this issue, the validity of Porter's approach has been effectively tested by other authors (Harrigan, 1980; Frazier \& Howell, 1983; Hinteruber, 1984; Pigni et al., 2002).

We therefore sought to identify the most strategic variables to describe the CMS segment. As there is no statistical method available to determine key variables, we identified them by reviewing previous analyses of CMS applications as described in the literature. The available research on the Software Industry and CMS applications (Robertson, 2002; Pelz-Sharpe et al., 2002; Brooks \& Princi, 2001; Nakano, 2002; Kekre et al., 1995; Cherns, 1993; Kunda \& Brooks, 2000; Sawyer, 2000; Gartner, 2001; Reynolds \& Kaur, 2000; Raghunathan, 2000; McKeever, 2003; Jaydip et al., 2003), suggested the most strategic variables were the number of CMS functions the application offered, and its cost. These literature review findings are consistent 
with McGahan's proposition on the importance of core assets to the software industry, where the number of functions appeared to constitute the added value for which customers were most willing to pay.

Nevertheless, we constantly monitored several dimensions of the CMS market throughout the study, such as the marketing strategies and technologies associated with each CMS application. This market monitoring revealed another variable, one unmentioned in the previous literature, but which emerged as strategic for the CMS segment: the services offered with the CMS application (e.g. training). Over the years of the study our CMS market monitoring allowed us to observe CMS companies re-directing their strategy towards differentiation based on the services offered with the CMS applications. This variable did not appear as strategically relevant in Phases 1 and 2, when numbers of services offered were limited, and were not levered on in CMS organisations' marketing strategies. But subsequent to Phase 2, we observed a shift in their core activities toward the delivery of services, with numbers of services offered increasing and being promoted by specific marketing campaigns. In fact, the growing strategic relevance of the services offered by CMS segment organisations can be seen as evidence of a change in their core activities, and we therefore decided to add the number of services offered as a third strategic variable for our study, and measure it in the final Phase 3.

\section{The strategic variables}

\section{The number of available functions}

The available functions of the CMS applications define the range of tasks each application can perform (Jaydip et al., 2003), which may cover different content management areas such as content creation, digital asset management and publication, among which we included the ability to import content from different applications. To measure this first strategic variable, we studied the different data analysis techniques (such as function points, weighted averages, hierarchical classifications) employed in previous similar research (Kunda \& Brooks, 2000). Reviewing the literature showed that the most common method consisted of simply counting the functions an application offered and giving them all equal importance, thus minimizing the subjectivity of the assessment associated with giving a hierarchical weighting to the relevance of different functions. (In fact, all the papers noted above employed this simple measurement methodology). Thus a list of functions, structured into different functional sections, was developed and applied, and the presence of each function on the list checked by examining each CMS application. Each function was noted with a 'yes' or 'no' to indicate its presence or absence, (Brynjolfsson \& Kemerer, 1996), with 'free add on' if the function could be freely integrated into the main application and 'not specified' if we could not be certain of its presence. Functions were regarded as 
included in a CMS application if they registered a 'yes' or a 'free add on' in our functionality database, and the total count was considered as our proxy of the functional strength or value of the CMS application (Table 4 in Appendix shows an extract of the structured list of functions and an example of how it was used in Phase 1).

Table 2 shows how the types of functional sections and overall numbers of available functions included in CMS applications grew over the longitudinal study period. As product features changed or were extended over time, our structured list of functions was revived and updated, and this development also meant that each phase of the longitudinal study involved re-designing our structured lists of functional sections and individual functions. Thus the second phase involved the addition of a new functional section and a considerable extension of the number of functions. The new functional section concerned the possibility of integrating the CMS application within other enterprise applications (e.g. with ERPs), since this had become a relevant feature for potential clients and had been exploited as a differentiation lever by the CMS developers. Similarly, at the third phase, the evolution of CMS functionality caused further changes, with the number of functions peaking at 194, and three new functional sections being added:

- a section grouping several functions on e-commerce (e.g. shopping cart management), to take into account the progressive integration of e-Commerce management within the CMS;

- a section gathering functions of security management (e.g. the LDAP authentication), dealing with the security concerns on the content and the transactions managed through the CMS applications;

- a 'built-in applications' section, listing the several small and complementary applications (such as chat, event manager) that were added to the main features of a CMS application.

\begin{tabular}{|c|c|c|c|}
\hline & Phase 1 (2002) & Phase 2 (2004) & Phase 3 (2007) \\
\hline Functional sections: & $\begin{array}{l}\text { 1. Content creation } \\
\text { 2. Digital asset management and publication } \\
\text { 3. Content localization } \\
\text { 4. Workflow management }\end{array}$ & 5. Application integration & $\begin{array}{l}\text { 6. E-commerce } \\
\text { 7. Security management } \\
\text { 8. Built-in applications }\end{array}$ \\
\hline Overall number of functions: & $=44$ & $+75=119$ & $+75=194$ \\
\hline
\end{tabular}

Table 2 Functional sections and number of functions in Phase 1 and additions in Phase 2 and in Phase 3

\section{The cost of the CMS application}

The second strategic variable in our framework was the cost of the CMS application, which we decided to include based on the CMS taxonomy proposed by the CMS Review portal (skyBuilders Inc., 2004; skyBuilders Inc., 2007) and applied in other studies (Ravarini, 2006; CMSWorks Inc, 2004) and is based on an overall estimate of the cost to an organization of obtain an entry level licence for the CMS application. In accordance with the CMS Review taxonomy, we split the CMS applications into 5 different categories, based on their 
estimated entry-level licence price range in thousand US\$. We followed the CMS Review portal in reflecting the general downward trend of entry level licence costs for the most expensive category, by lowering the starting licence price for this category from US $\$ 176,000$ to US $\$ 151,000$ from 2007 onwards. Albeit clearly a proxy of the actual licence cost of a CMS application, this taxonomy was considered adequate for the purpose of our research. As the focus of our study was represented by changes in costs over time, and the cost differences between different CMS applications, a more precise cost estimation would have added little significant value to our research. The cost categories and entry level licence costs are shown in Table 3.

\begin{tabular}{|l|c|c|c|}
\hline & \multicolumn{3}{|c|}{ Entry level license cost in K\$ } \\
\hline Category & Phase 1 (2002) & Phase 2 (2004) & Phase 3 (2007) \\
\hline Enterprise & $176-250$ & $176-250$ & $151-250$ \\
\hline Upper tier & $101-175$ & $101-175$ & $101-150$ \\
\hline Middle market & $26-100$ & $26-100$ & $26-100$ \\
\hline Lower priced & $1-25$ & $1-25$ & $1-25$ \\
\hline FLOSS & 0 & 0 & 0 \\
\hline
\end{tabular}

Table 3 CMS taxonomy

\section{The number of services offered}

The third and final strategic variable was the services offered as complements to the CMS application. As noted above, in monitoring the CMS market over the study period we observed CMS companies re-directing their strategies towards a differentiation based on services offered alongside the CMS applications, and therefore included services offered as our third strategic variable. 22 different services were identified at the third phase of the longitudinal study, including the availability of documentation on the CMS or host application possibilities. As with the data collection for the CMS functions, each service received a 'yes' if the service was offered, 'no' if the service was unavailable, or 'not specified' if we were unsure about its offer, and the variable was measured by the number of 'yes' registrations on our database.

\section{The longitudinal study}

\section{CMS selection}

Changes in the software market had a direct impact on the choice of CMS applications analysed during the period of our longitudinal study. At each of its three phases, a new set of CMS applications was selected and added to those used in the previous phase. For the precise purpose of our research, the first criteria used to select a CMS application was the availability of data on the functions and the licence price category, as the two key variables in explaining the evolution of the change trajectories in the CMS segment. 
At Phase 1, several CMS applications were selected because they figured among the market leaders and had heterogeneous origins in terms of software segments in which they had previously operated. Subsequent to this phase, we observed many other applications entering the CMS market, with numbers of functions offered increasing, prices evolving, and FLOSS CMS applications emerging as an effective alternative to packaged offerings. We therefore decided to develop our Phase 1 work into a longitudinally study by examining the CMS market a second time. We redefined our set of CMS applications for Phase 2 to include a new range of packaged CMS applications, and a set of FLOSS applications, but without losing sight of the need for sample heterogeneity. Our Phase 2 sample emphasized FLOSS applications, as they represented the biggest novelty over Phase 1, and only retained the four most well-known CMS applications from Phase 1 into at Phase 2. At Phase 3, the emergence of some new players onto the CMS market led us again to add more applications into the previous set.

For the purpose of managing our study and its data collection, we opted to choose a set of CMS applications that, as a whole, would best represent the whole field in terms of the range of functions offered and of licence costs. We identified three parameters as proxies of such choice: the market share of the application, the achievement of awards and how different the CMS applications were in terms of functions each offered. Erreur ! Source du renvoi introuvable. in the Appendix shows how the list of applications studied grew for each phase, together with the reasons for including each in the sets.

\section{Data collection}

Data was collected from primary sources (i.e. directly testing the CMS applications) and secondary sources, such as browsing CMS application web sites, reading paper-based and electronic-based journals, reports and articles (Kunda \& Brooks, 2000; Jaydip et al., 2003), and stored on a database, which also recorded the values relating to the selected strategic variables for each CMS application analysed. Phase 1 data collection took place in May 2002, and Phase 2 collection in November 2004. Market monitoring over the 29 months between these phases revealed the CMS segment to have evolved in function and cost terms sufficiently - in particular, with the rapid appearance of new versions of many existing CMS applications boasting several new functions - to allow us to define significant differences between the two phases.

After Phase 2, our continued regular monitoring the CMS market revealed a slight decrease in the pace of new version releases, and thus Phase 3 data collection was delayed until September 2007, some 34 months after Phase 2. However, our monitoring also revealed that some new CMS applications, either non-existent or extremely marginal in 2004, had emerged as significant players in the market, again offering new sets of 
functions. Moreover, while the pace of innovation in packaged CMS applications had slowed, FLOSS CMS applications registered a number of important improvements. Finally, the Phase 3 data collection revealed that CMS organizations had re-directed their strategy towards offering differentiated services, which led us to include services as our third strategic variable, so as to understand the trajectory of changes in the CMS segment more completely.

\section{Data analysis}

The collected data on the three measured strategic variables is presented on scatter graphs in the Results section and reported in tables in the Appendix. The scatter charts position each product as a mark on the chart defined by axes representing two of the three strategic variables, and facilitate the exploration of the relationships between cost category, functions and services. The graphs are complemented by Spearman Correlation coefficients which measure the correlation of two ordinal level variables so that their significance and value can be assessed. This statistical tool gives quantitative support to the qualitative analysis of the CMS applications, based on the strategic grouping approach and reinforcing (as far as the sample size allows) our results and the discussions on the evolutions of CMS applications over time.

\section{Results}

The results of the empirical study follow our data collection timeline: first, three separate pictures of the CMS market at different times are presented, after which the whole data set is used to draw the trajectory of the CMS application change over time.

\section{Phase 1 - 2002}

The first phase illustrates the heterogeneity of the 4 CMS applications we analysed in terms of the functions and costs. The number of available functions varies from 14 to 26 , depending on the application, while the cost categories range from lower priced (for Microsoft CM Server 2001) to middle market (for the other three applications in the set). Figure 2 represents the scatter chart results, while Table 6 in Appendix gives the details. 


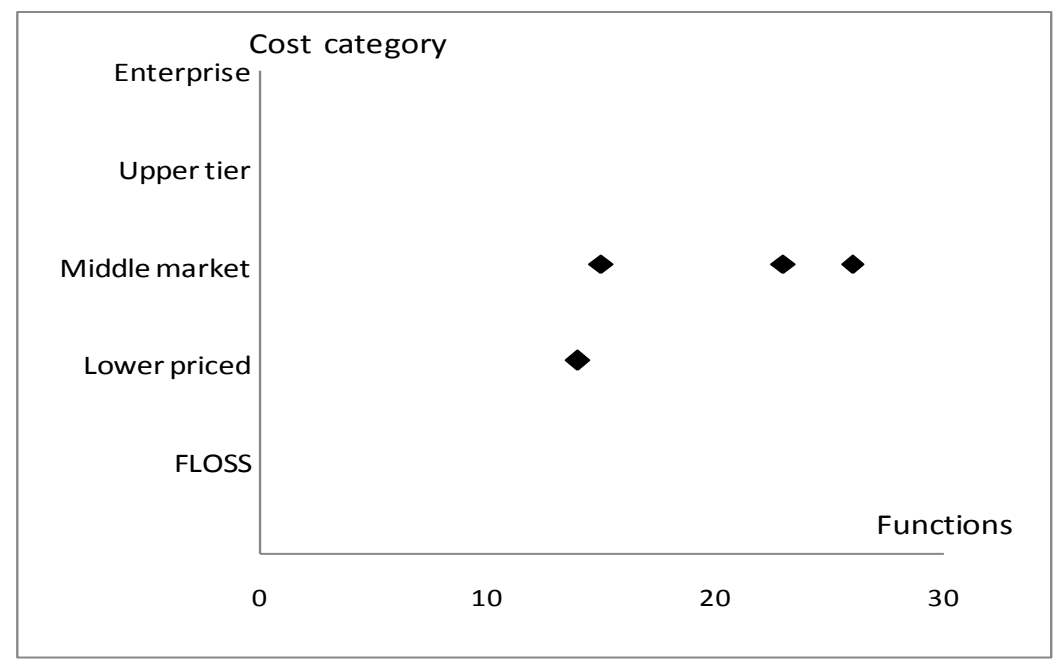

Figure 2 The functionality and cost distribution of CMS applications at Phase 1

\section{Phase 2 - 2004}

At the second Phase, in terms of functions, the gap between the most and fewest functions offered by applications was 74 functions wide, ranging from 33 functions for Obinary ltd. Magnolia CMS 1.1 to 107 functions for Vignette V7. In cost terms, this phase registered the widest gap, spanning the whole breadth of our cost taxonomy between the FLOSS and the Enterprise categories. While the FLOSS applications are free, packaged CMS costs are spread among the Middle Market, Upper Tier and Enterprise categories. Generally, at this phase, FLOSS applications are less function-rich than packaged CMS applications, although some (such as TYPO3 3.7, Zope \& Plone 2.0.49) offer more functions than some packaged applications. The scatter chart of Figure 3 highlights the marginal gap in terms of number of functions between FLOSS and packaged CMS and the wide cost gap between the two (see Table 6 in the Appendix for details). Nevertheless a general correlation between costs and functions is distinguishable, and is confirmed by the Spearman Correlation coefficient figure of 0.593 significant at 0.01 . 


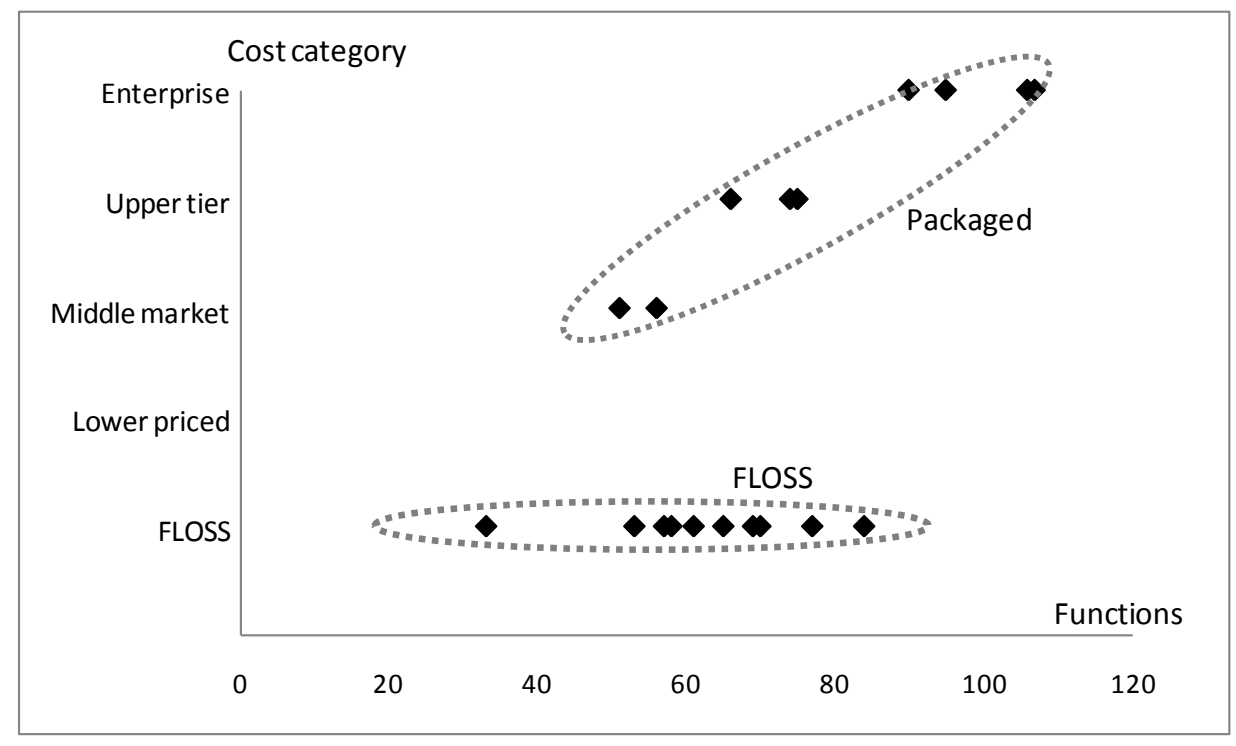

Figure 3 The functionality and cost distribution of CMS applications at Phase 2

\section{Phase 3 - 2007}

At Phase 3, as far as functions are concerned, a 79 point gap exists between Outerthought Daisy 2.0 (with only 103 functions) and Documentum EMC 5.3 (with 182). Even though the most 'function-poor' application is a FLOSS application and the most function-rich a packaged application, there is no clear overall separation between the two sectors in terms of numbers of functions: many FLOSS CMS offer as many (or more) functions as many packaged CMS. In terms of costs, there are now no CMS applications in the Enterprise and Upper Tier cost categories, so the overall cost span is much reduced, to that between the FLOSS category and the Middle Market cost category for some packaged CMS applications. Figure 4 shows a clear demarcation between the FLOSS and packaged sectors in cost terms, but the picture is much less clear-cut in terms of functions, with both types regularly distributed all along the Functions axis. This lack of a clear correlation between cost and functions is supported by the lack of significance of the Spearman Correlation coefficient: in Phase 3, the number of available CMS functions appeared to be unrelated to application cost. 


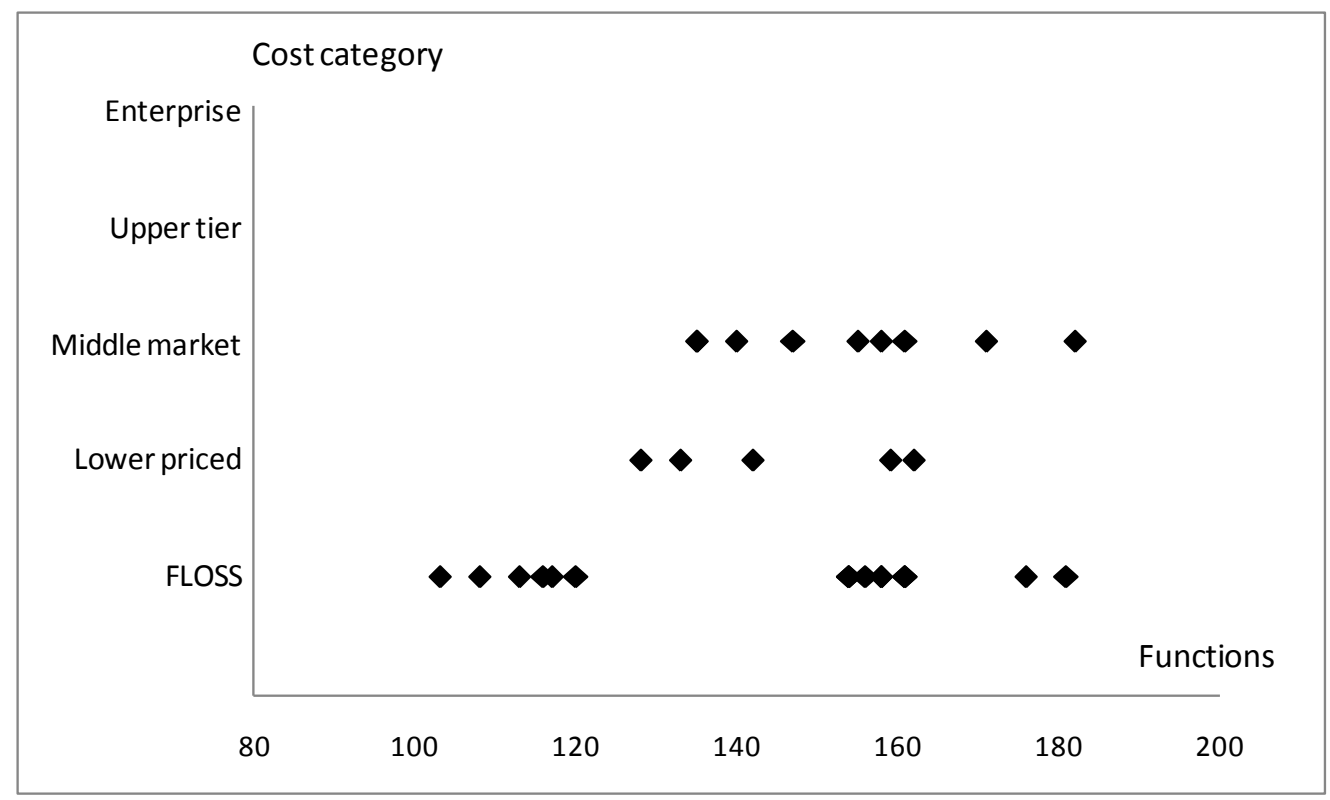

Figure 4 The functionality and cost distribution of CMS applications at Phase 3

However, when we look at the distribution of services (the variable measured for the first time at Phase 3), we found a correlation between the cost category and the number of services offered. Generally speaking, the more expensive the application, the higher the number of services offered, with the number of services offered by packaged applications being higher than that offered by FLOSS applications (again, see Table 6 in the Appendix for details). A deeper analysis - as depicted in the Figure 5 scatter chart - allows two sets of CMS to be identified: set A includes CMS offering many services but dispersed across the three lower cost categories, while set B includes applications offering fewer services (which are also all FLOSS applications). Costs and services are also positively correlated statistically, with a Spearman Correlation coefficient of 0.694 , significant at 0.01 .

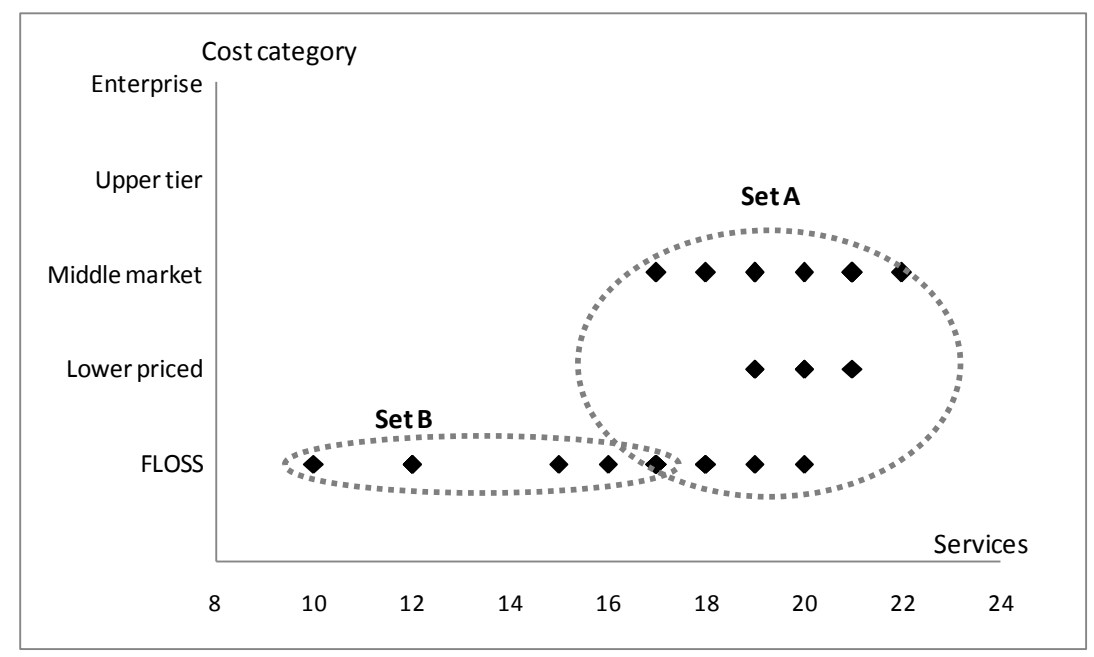

Figure 5 The cost and service distribution of the set of applications at Phase 3 
Looking at all three variables together (Figure 6), the data again shows a relationship between functions, cost and services offered, although this time there is no statistical significance. Set $\mathrm{C}$ is composed of products offering the most services and functions, and includes all the packaged applications as well as several FLOSS applications CMS, while, in comparison, set D consists of applications offering the fewest services and functions, which are all FLOSS products.

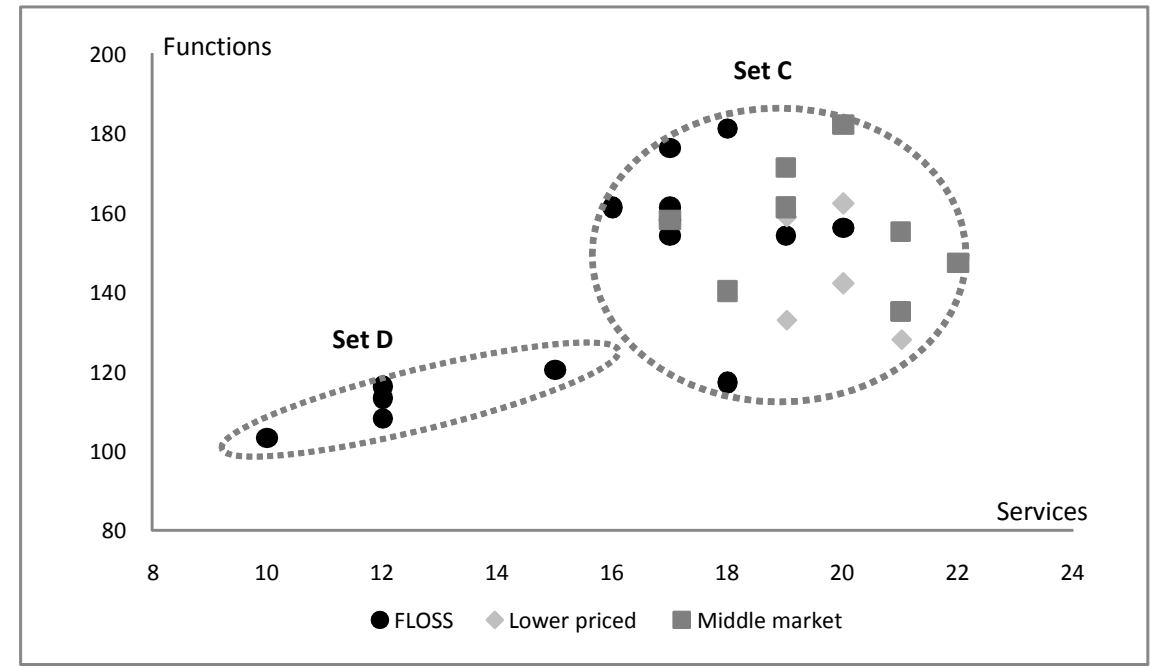

Figure 6 The functionality, cost and services distribution of the set of applications at Phase 3

\section{Results across the phases}

The box plot in Figure 7 synthesizes the evolution of the number of functions along the longitudinal study. However, comparing our observation period data calls for some care. First, the number of functions available in the CMS applications increases over time for two main raisons. On the one hand, the applications added new functions as part of the developers' continuous updating of their software functionality. On the other hand, to keep the pace with this functional extension, we extended the structured list of the functions we measured, so previously uncounted functions we now included. Hence a direct application by application comparison between the numbers of functions across the three phases would make little sense. 


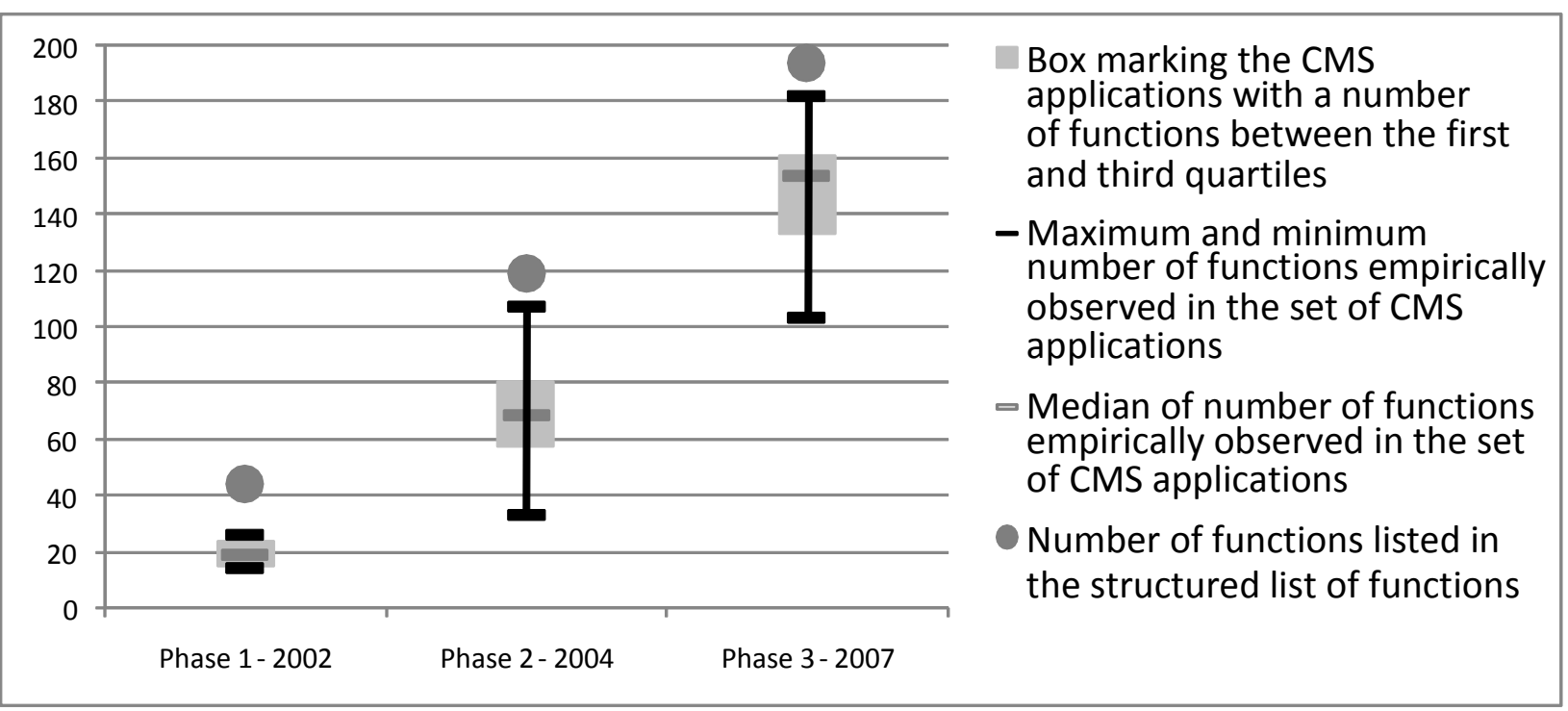

Figure 7 The evolution of the number of functions across time

Second, as previously noted, the cost category taxonomy (see Table 3) changed slightly during the study, with the boundary between Upper and Enterprise and tier categories being adjust downwards somewhat: however, this may not be germane, as we found no CMS applications in either cost category in Phase 3.

We therefore only discuss the general trajectories over time, and our data analysis identifies three main changes:

1. The increase in the number of available functions, where the rate of increase was higher for FLOSS CMS than for packaged applications, which contributed to the gap between the numbers of functions offered by packaged and FLOSS applications evening out by 2007;

2. The cost of the applications, which generally rose between Phases 1 and 2, and then decreased between Phases 2 and 3;

3. The emergence of services offered as a new strategic variable in the CMS segment between Phases 2 and 3.

These three changes point to the rising market strength of FLOSS CMS applications. Between 2002 and 2004 packaged CMS developers combined extending available functionality with increasing entry level licence costs, with the greater number of functions of packaged CMS applications differentiating their offers from those of the cost-free FLOSS applications. However, between 2004 and 2007, the functional extensions of FLOSS CMS flushed away the function-based differentiation between the two types.

The heightened competition among CMS products post 2004, and the increasing difficulties packaged CMS developed had in maintaining function-based differentiation in the market, are also highlighted by two other changes. First, packaged software firms made significant reductions in the entry level licence costs for their 
products. In Phase 2, most packaged applications were in the two most expensive categories in our taxonomy, but by Phase 3, all bar one had cut their licence costs (some very heavily), so by 2007 they all appeared in the lower two cost categories. Second, packaged CMS applications included a much wider range of services as part of their offer and put an accentuated emphasis on this factor in their marketing strategies. Thus differentiation in this market seems to have moved from being function-based to being service-based, and in terms of this strategic variable, the packaged CMS products (or at least some of them) seem to have a significant advantage over most FLOSS applications.

\section{Discussion}

Our longitudinal data collection highlights the changes of CMS applications in terms of functions, costs and the offer of related services over a six-year period. In line with previous studies, we have observed a considerable and general increase in application functionality over time (Wilkoff, 2001; Basili \& Boehm, 2001; Latham, 2007b). At Phase 1, CMS functions tended to be fairly strictly related to content management, but subsequently expanded to support other management fields such as e-commerce, knowledge management and document management, blurring even further the already fuzzy boundaries between these different types of applications, as predicted in previous research (Howard, 2001; Wilkoff, 2001; Pelz-Sharpe et al., 2002).

Moreover, the practice of marketing frequent new-version releases that often include several new functions (Adam \& Light, 2004) leads to the rapid obsolescence of previous versions and pushes the existing customers to upgrade their CMS applications. The developers of packaged CMS can benefit from this practice by charging clients for an expensive upgrade (Sawyer, 2000) and activating lock-in (Adam \& Light, 2004) policies. We have seen that the evolution of packaged CMS costs has followed a parabolic trend. The initial increase in the cost and functions of packaged CMS was in line with a differentiation strategy against the emerging FLOSS CMS applications, which in 2004 were considerably less rich in functionality. But, by 2007, that fact that functionality had subsequently expanded faster in FLOSS than in packaged CMS seems to have led to a decrease in packaged CMS costs (Sawyer, 2000). In fact, it now seems unlikely that a packaged application could compete on costs against a FLOSS application (Adam \& Light, 2004).

This kind of cost reduction, combined with the increase in the number of available functions, is consistent with the general expected trend of declining cost-to-performance ratio over time of IT assets in general (Demirhan et al., 2007), and software in particular (Liebowitz \& Margolis, 1999), where earlier entrants suffer cost disadvantages in comparison to followers. To try to counter this trend, packaged CMS developers appear to have chosen a new differentiation strategy against FLOSS CMS, by developing and marketing an 
increasing range of services to their clients (Adam \& Light, 2004; Andersson \& Nilsson, 1996). We believe this differentiation strategy will be sustainable, in that FLOSS CMS will not offer the same wide range of services, at least in the short term. In fact, this differentiation strategy does not seem easy for FLOSS CMS to replicate unless a leading company undertakes the development of a full range of services. We expect a further and gradual extension of the offer of services in the segment as a whole, as the tendency towards a service-based business model is one that is expected in maturing markets, and that has already been described both for the software industry (Cusumano et al., 2006) and for FLOSS (Fitzgerald, 2006).

\section{Informing McGahan's theory}

These results allow us to draw a general picture of the evolution of the CMS segment's core assets and core activities - in other words, they make it possible to map the CMS segment onto the framework of the Industry Change Trajectory Theory (McGahan, 2004b) in order to inform it. Our longitudinal study has allowed us to observe the continuous development of CMS applications and the sustained extension of the number and types of their functions. This pattern suggests that the core assets of the CMS segment (i.e. the software applications themselves) are highly affected by the threat of obsolescence. With respect to the second dimension of McGahan's framework - the core activities - our research highlights the emergent phenomenon of the diffusion of the practice of providing services as well as delivering of software solutions, a development that represent a major change in the segment's core activities. The results of the study indicate, therefore, that the evolution of the CMS segment has been following a 'radical change' trajectory - a conclusion that invites further discussion, since it is not aligned with McGahan's general thesis of the software industry following a creative change trajectory.

Looking more closely, the development of new functions by FLOSS CMS developers appears faster than by packaged CMS developers, who no doubt see their position in the segment as being threatened by FLOSS CMS, which are now becoming as rich in functionality, but inevitably remaining cheaper. We believe packaged CMS developers are reacting to the obsolescence of their applications through the development of new activities for the delivery of services - which are core to them as they aim at 'generating greater willingness to pay among the industry's buyers' (McGahan, 2004b). While some FLOSS CMS applications contain service elements, freely available and provided by the FLOSS community itself, they do not appear as rich or broad as those associated with packaged CMS. However, the change toward services of packaged CMS developers is at risk from at least three different new threats from the FLOSS community. First, if a formal company sponsors the development of FLOSS CMS, it is possible it could offer the same full range of services as packaged CMS. 
Some companies (e.g. Obinary) leading the development of FLOSS CMS have adopted this service strategy, and are structuring their business model around the offer of services (Fitzgerald, 2006). Second, applications developed by the FLOSS CMS community may attract the attention of commercial companies who may see a new business opportunity in offering services built over community-developed FLOSS CMS applications (Fitzgerald, 2006; Dahlander \& Magnusson, 2008). Third, some very active development communities (e.g. the Typo3 and Plone communities) have already successfully developed rich offers of services, which seem to match those available from some commercial companies.

These threats to the commercial companies' core activities seem to confirm that the CMS segment is following a radical change trajectory, a result that has important implications in terms of how a company should manage this change trajectory. When the industry is subject to a creative change trajectory, McGahan suggests putting a lot of effort on high-risk/high-potential projects, in a sort of trial-and-error approach that can be quickly abandoned in case of failure. However, where their change trajectory is radical, McGahan recommends that organizations gradually and cautiously plan and execute their exit from unprofitable activities and expand their most profitable ones, leveraging on the flexibility accorded by their short-term assets. Hence, a radical change trajectory has a long-term impact for CMS organizations, which have to consistently change their strategies. Even if radical change transforms an industry completely, it will take time, as the erosion of assets and activities will be gradual (McGahan, 2004b), and organizations can remain profitable during such change if they manage it gradually and intelligently, and develop strategic and emerging lines of business to cope with the situation. Thus firms developing CMS applications should gradually develop new business models, which might include exploiting the open source code and products freely available on the market. They could also take advantage of the competences of their users by involving them in the improvement of the CMS applications and giving them more freedom to modify the applications for development purposes.

This study does not provide direct evidence of the possibility of generalizing from these results. However, the fact that the growth of FLOSS projects and the trend toward services are generalized phenomena in the software industry (Fitzgerald, 2006; Rai \& Sambamurthy, 2006) suggests that these results could be reproduced in other segments - indeed, it has already been observed in the computer platform segment (West, 2003). Microsoft, and others companies whose packaged applications lead the software market are gradually and cautiously planning and enacting the re-orientation of their business models, and starting to distribute open source products, to use open source code in their applications and to authorize licensees to review, modify, redistribute, and sell works with no royalties (Matusow, 2005; Roy, 2003). They are also trying to replicate the 
open source development process, through globally distributed developments, independent peer reviews of code source and reacting to users' experience and input (Fitzgerald, 2006).

\section{Conclusions and further research}

This paper discusses the trajectory of change in the CMS segment through a six-year longitudinal study of a set of CMS applications that, following the Porter's strategic grouping approach (Porter, 1980), have been measured in terms of available functions, cost and offer of services. We have observed an increase in the number of functions of CMS applications, a parabolic trend in the cost of packaged CMS applications, and the emergence of services as a new strategic variable. Taking Industry Change Trajectory theory into account, these outcomes suggest that the CMS segment has been following a 'radical change' trajectory. The core assets of the CMS developers (i.e. their CMS applications) are constantly threatened by obsolescence by the rapid pace of functionricher releases of CMS applications by competitors, and this threat in turn increases the pressure on them to continuously redevelop their own applications. At the same time, competition between packaged and FLOSS CMS applications has lead to the shift to new core activities, towards supporting the offer of services.

These results contradict the positioning proposed by McGahan (McGahan, 2004b), who probably did not take into account the shift towards commoditization (Carr, 2003) and services in the IT industry (Rai \& Sambamurthy, 2006) and the emerging phenomena of FLOSS software (Fitzgerald, 2006; West, 2003) - in fact, neither did we in our 2002 Phase 1 data collection. In 2004, in contrast, we did quite the opposite, since we took into account FLOSS applications almost exclusively. In the end, only four packaged CMS applications remained in all three of our examined sets from 2002 through to 2007, although this did not reduce the validity of our findings.

Once the CMS segment is correctly positioned among the four different trajectories (in the Radical Change trajectory quadrant), the normative side of the Industry Change Trajectory Theory (McGahan, 2004b) gives lessons for the segment and for the software industry as a whole: to gradually re-orientate the business model onto the more profitable activities (such as service delivery) and/or scale back unprofitable activities (such as in-house packaged software development) (Fitzgerald, 2006). In addition to informing the Industry Change Trajectory Theory by examining data about the actual trajectory of the CMS segment, this study contributes to the research on the Open Source software transformation (Fitzgerald, 2006), thanks to its longitudinal approach and the direct comparison of FLOSS and packaged software within a single software segment.

Given the general relevance of the phenomena we have described, similar evolutionary paths may be recognized in other software industry segments, as some empirical evidence has already shown. But speculation 
as to whether our results hold good for other segments will need further empirical testing. While we will continue to observe the CMS segment, we consider the exploration of some other software industry segments as an interesting research field for developing a better understanding of possible differences in change trajectories. Another area of exploration could be the assessment of the relationship between company performance and industry change trajectory at different levels (firm, strategic group, industry), following (for instance) the methodology proposed by Short et al. (Short et al., 2007). 


\section{References}

ADAM A and LIGHT B (2004) Selling packaged software:An ethical analysis. In European Conference on Information Systems, Turku, Finland.

AIIM (2002) Entreprise applications - adoption of e-business and document technologies: 2000-2001. Commissioned by AIIM (Association for Information and Image Management - The Entreprise Content Management Association) and conducted by Gartner.

ANDERSSON R and NILSSON AG (1996) The standard application package market - an industry in transition? In Advancing your business: People and information systems in concert (LUNDEBERG M and SUNDGREN B, Eds), pp 1-24, EFI, Stockholm School of Economics, Stockholm.

BASILI V and BOEHM B (2001) Cots-based systems top 10 list. IEEE Computer 34(5),

BeLl T, SHEGDA KM, DRAKOS N, KNOX RE and LOGAN D (2007) Cool vendors in content management, 2007. Research, Gartner, p 6.

BOONSTRA A (2003) Structure and analysis of is decision-making processes. European Journal of Information Systems 12(3), 195.

BRADLEY JH, PAUl R and SeEMAN E (2006) Analyzing the structure of expert knowledge. Information \& management 43(1), 77-91.

BROOKS JD and PRINCI M (2001) Entreprise content management: Better information to more people more quickly. Accenture, p 4.

BRYNJOLFSSON E and KEMERER CF (1996) Network externalities in microcomputer software: An econometric analysis of the spreadsheet market. Management Science,

CARR NG (2003) It doesn't matter. HBR at large,

CHERNS A (1993) Principles of socio-technical design. In The social engagement of social science (TRIST E and MurRay H, Eds), University of Pennsylvania Press.

CMSWORKS INC (2004) Cms watch. CMSWorks Inc,.

COMTEX (2002) Frost \& sullivan names ibm the leader in entreprise content management. Internet Wire, p 2.

CuSUMANO M, KAHL S and SUAREZ FF (2006) Product, process, and service: A new industry lifecycle model. MIT.

DAHLANDER L and MAGNUSSON M (2008) How do firms make use of open source communities? Long Range Planning 41(6), 629-649.

DEMIRHAN D, JACOB VS and RAGHUNATHAN S (2007) Strategic it investments: The impact of switching cost and declining it cost. Management Science 53(2), 208-226.

Driver M, Alvarez G, Basso M, BitTerer A, Dawson P, Maio AD, Drakos N, Duggan J, Feinberg D, FIERING L and FRIEDMAN T (2008) Hype cycle for open-source software, . Gartner, p 47.

ECONOMIDES N and KATSAMAKAS E (2006) Two-sided competition of proprietary vs. Open source technology platforms and the implications for the software industry. Management Science 52(7), 1057-1071.

FITZGERALD B (2006) The transformation of open source software. MIS Quarterly 30(3), 587-598.

FRANKL P and RUBIK F (2000) Life cycle assessment in industry and business:Adoption patterns, applications and implications. Berlin.

FRAZIER GL and HOWELL RD (1983) Business definition and performance. Journal of Marketing 47(1), 59-67.

FREE SOFTWARE FOUNDATION (2007) The free software definition. Free Software Foundation.

GARTNER G (2001) Entreprise application - adoption of e-business and document technologies: 2002-2001 worldwide. AIIM International.

GUTSCHE J (2005) Competition between open source and proprietary software, and the scope for public policy. In International Conference on Open Source Systems, Genova, Italy.

HARRIGAN KR (1980) Strategies for declining industries. L. Books,

HINTERUBER G (1984) The analysis of strategic groups of firms. Economia Aziendale 3 ,

HOWARD P (2001) Selecting a content management provider. In Content Management (ELM, Ed), Ericleach, London.

IZUSHI H and AOYAMA Y (2006) Industry evolution and cross-sectoral skill transfers: A comparative analysis of the video game industry in japan, the united states, and the united kingdom. Environment and Planning 38(10), $1843-1861$.

JAYDIP MR, KAI SK, LAI CL and CHUN SY (2003) An identification and classification of enterprise portal functions and features. Industrial Management + Data Systems 103(8/9), 693-702.

KEKRE S, KRISHNAN MS and SRINIVASAN K (1995) Drivers of customer satisfaction for software products: Implications for design and service support. Management Science 41(9), 1456-1470.

Konana P and RAY G (2007) Physical product reengineering. Communications of the ACM 50(10), 72-78.

KUNDA D and BROOKS L (2000) Identifying and classifying processes (traditional and soft factors) that support cots component selection: A case study. European Journal of Information Systems 9(4), 226.

LATHAM L (2007a) Key issues for web content management, 2007. Research, Gartner, p 6. 
LATHAM L (2007b) Marketscope for web content management, 2007. Research, Gartner, p 17.

LEEBAERT D (1995) News from the frontiers. In The future of software (LEEBAERT D, Ed), MIT-Press, Cambridge, MA, USA.

LEVY M and POWELL P (2000) Information systems strategy for small and medium sized enterprises: An organisational perspective. The Journal of Strategic Information Systems 9(1), 63-84.

LIEBOWITZ SJ and MARGOLIS SE (1999) Winners, losers and microsoft competition and antitrust in high technology. The Independent Institute, Oakland, CA.

MATUSOW J (2005) Shared source: The microsoft perspective. In Perspectives on free and open source software (Feller J, B.FitzGERALD, Hissam S and LAKHANi K, Eds), pp 329-346, MIT Press, Cambridge, MA, USA.

MCGAHAN A (2004a) How industries evolve: Principles for achieving and sustaining superior performance.

MCGAHAN AM (2004b) How industries change. Harvard Business Review 82(10), 86-94.

MCGAHAN AM, ARGYRES N and BAUM JAC (2004) Context, technology and strategy: Forging new perspectives on the industry life cycle. In Business strategy over the industry life cycle (BAUM JAC, Ed), Elsevier.

MCKEEVER S (2003) Understanding web content management systems: Evolution, lifecycle and market. Industrial Management \& Data Systems 103(8/9), 686-692.

Melville N, GURBAXANi V and KRAEMER K (2007) The productivity impact of information technology across competitive regimes: The role of industry concentration and dynamism. Decis. Support Syst. 43(1), 229242.

MELVILlE NP, GURBAXANI V and KRAEMER KL (2005) It business value and industry effects: The role of the competitive environment.

NAKANO R (2002) Web content management. Addison-Wessley, Boston, USA.

PANG A (2008) Worldwide packaged applications 2008-2012 forecast and 2007 vendor shares: 2008 reference guide. Market Analysis, IDC.

PAulson J, SUCCI G and EBERLEIN A (2004) An empirical study of open source and closed source software products. IEEE Transactions in Software Engineering 30(4), 246- 256.

PElZ-ShARPE A, ASHENDEN A and HARRIS-JONES C (2002) Ovum evaluates: Content management. Ovum.

PICKETT JP (2000) The american heritage dictionary of the english language. Houghton Mifflin Company, Boston.

PIGNi F, RAVARINI A, TAgLiAVINI M and VitARI C (2002) Banks' strategies and the internet: An interpretation of the banking industry based on the italian retail market. Journal of Information Technology Cases and Applications 4(3),

POLLOCK N and WiLliAMS R (2008) The sociology of a market analysis tool: How industry analysts sort vendors and organize markets. University of Edinburgh, Edinburgh, UK, p 47.

PORTER ME (1980) Competitive strategy. Techniques for analyzing industries and competitors. The Free Press, New York.

PRICE WATERHOUSE (1998) 1998 software business practice survey. Boston, USA.

QUINTAS P (1994) The commodification of software. Information Technology \& People 7(4), 1-22.

RAGHUNATHAN S (2000) Software editions: An application of segmentation theory to the packaged software market. Journal of Management Information Systems 17(1), 87-113.

RAI A and SAMBAMURTHY V (2006) Editorial notes--the growth of interest in services management: Opportunities for information systems scholars. Information Systems Research 17(4), 327-331.

RAVARINI A (2006) Content management: How to be content with your solution. Cutter Benchmark Review 6(4), 18.

REPORTSURE (2005) Global software and it survey. Industry Survey, ReportSURE, p 154.

REYNOLDS J and KAUR A (2000) Content management. Microsoft, p 30.

ROBERTSON J (2002) How to evaluate a content management system. KM Column, 6.

RoY A (2003) Microsoft vs. Linux: Gaining traction. Chartered Financial Analyst 9(5), 36-39.

SAWYER S (2000) Packaged software: Implications of the differences from custom approaches to software development. European Journal of Information Systems 9(1), 47.

ShORT JC, KeTCHEN DJJ, PALMER TB and Hult GTM (2007) Firm, strategic group, and industry influences on performance. Strategic Management Journal 28(2), 147-167.

SKYBUILDERS INC. (2004) Cms review feature list. skyBuilders Inc.

SKYBUILDERS INC. (2007) Cms review feature list. skyBuilders Inc.

SuCCI G, PAULSON J and EBERLEIN A (2001) Preliminary results from an experimental study on the growth of open source and commercial software products. In ICSE Workshop on Economics-Driven Software Engineering Research, Toronto, ON, Canada.

UsORO A (2001) Can information technology help managers plan globally? Journal of Global Information Management 9(1), 17 - 24.

VOAS J (1998) Cots software: The economical choice? IEEE Software 15(2), 16-19. 
VOAS J (2001) Faster, better, cheaper. IEEE Software, 96-97.

WALLNAU K (1999) On software components and commercial ('cots') software. In International Workshop on Component-Based Software Engineering, Los Angeles, CA, USA.

WEST J (2003) How open is open enough? Melding proprietary and open source platform strategies. Research Policy 32, 1259-1285.

WILKOFF N (2001) What's next for content management? , Forrester Research Inc., Cambridge, p 4.

WINTERGREEN RESEARCH (2005) Content management market opportunities, strategies, and forecasts, 2005 to 2011. Wintergreen Research, p 496.

\section{Appendix}

\begin{tabular}{|c|c|c|c|c|c|}
\hline \multirow[t]{2}{*}{ Functional section } & \multirow[t]{2}{*}{ Function } & \multicolumn{4}{|c|}{ Phase 1 - May 2002} \\
\hline & & $\begin{array}{c}\text { Documentum ECM } 4 \mathrm{i} \\
\text { version } 4\end{array}$ & $\begin{array}{l}\text { Microsoft CM } \\
\text { Server } 2001\end{array}$ & $\begin{array}{c}\text { Interwoven TeamSite } \\
\text { version } 5\end{array}$ & $\begin{array}{l}\text { Vignette Content } \\
\text { Suite version } 6\end{array}$ \\
\hline \multirow{12}{*}{ Content Creation } & $\begin{array}{l}\text { Knowledge of HTML not } \\
\text { required for content creation }\end{array}$ & yes & yes & yes & yes \\
\hline & $\begin{array}{l}\text { Importing content from } \\
\text { different documents and } \\
\text { applications }\end{array}$ & yes & yes & yes & yes \\
\hline & $\begin{array}{l}\text { RSS reception and } \\
\text { integration }\end{array}$ & yes & no & yes & No \\
\hline & Web site template definition & yes & yes & yes & Yes \\
\hline & Content asset repository & yes & yes & yes & Yes \\
\hline & Metadata Management & yes & yes & yes & Yes \\
\hline & Tag management & yes & not specified & not specified & not specified \\
\hline & $\begin{array}{l}\text { Internal web site link } \\
\text { management }\end{array}$ & yes & not specified & not specified & not specified \\
\hline & $\begin{array}{l}\text { External web site link } \\
\text { management }\end{array}$ & yes & not specified & not specified & not specified \\
\hline & $\begin{array}{l}\text { Metadata based search } \\
\text { engine }\end{array}$ & yes & no & yes & No \\
\hline & $\begin{array}{l}\text { Content-based search } \\
\text { engine }\end{array}$ & yes & no & yes & No \\
\hline & $\begin{array}{l}\text { Semantic-based search } \\
\text { engine }\end{array}$ & no & no & no & No \\
\hline \multirow{8}{*}{$\begin{array}{l}\text { Digital Assets } \\
\text { Management and } \\
\text { Publication }\end{array}$} & $\begin{array}{l}\text { Automatic Digital Assets } \\
\text { Versioning }\end{array}$ & no & no & yes & No \\
\hline & Version control & yes & yes & yes & Yes \\
\hline & Digital Assets Repository & no & no & yes & No \\
\hline & File lock on open & yes & yes & yes & Yes \\
\hline & Conflict Resolution System & no & no & yes & No \\
\hline & $\begin{array}{l}\text { Staging or Pre-Publication } \\
\text { of the site or of the page }\end{array}$ & yes & yes & yes & No \\
\hline & Publication on PDAs & no & no & no & No \\
\hline & Publication on PCs & yes & yes & yes & Yes \\
\hline
\end{tabular}

Table 4 An extract of the structured list of functions and an example of how it was used for the data collection in the Phase 1

\begin{tabular}{|l|l|}
\hline CMS application & Reasons for inclusion in set \\
\hline Retained from Phase 1 & \\
\hline Documentum ECM 4i 4 & $\begin{array}{l}\text { In 2002, Documentum was an enterprise specialized in Document Management Systems (DMS) and Content } \\
\text { Management Systems. Its DMS application evolved over the years into a CMS application. We were interested to } \\
\text { see the characteristics of this CMS application which was originally a DMS. }\end{array}$ \\
\hline Interwoven TeamSite 5 & $\begin{array}{l}\text { Interwoven was a company which started up with a CMS application and, in 2002, it was still the only application } \\
\text { offered. In 2002 the company held the biggest CMS market share, so we included it for its wide diffusion. }\end{array}$ \\
\hline Microsoft CM Server 2001 & $\begin{array}{l}\text { Microsoft was selected because it is the world's biggest software corporation. hence it has the potential to be a } \\
\text { leader also in the CMS segment. }\end{array}$ \\
\hline Vignette Content Suite 6 & $\begin{array}{l}\text { Vignette, like Interwoven, is a company which started up with a CMS application. We included the CMS application } \\
\text { as it distinguishes itself through its advanced and celebrated IDE and API technological solutions which seem } \\
\text { superior to traditional CGI/vi/Perl Web development solutions. }\end{array}$ \\
\hline Added at Phase 2 & $\begin{array}{l}\text { FLOSS CMS became a Top Level Project of the Apache Software Foundation, in September 2004 and } \\
\text { consequently obtained formal support to become a leading CMS, as the web server Apache leads its industry } \\
\text { segment. }\end{array}$ \\
\hline Apache Lenya 1.2 & $\begin{array}{l}\text { FLOSS CMS which pursued its differentiation from the other FLOSS CMS through an accentuated separation } \\
\text { between design and content in order to achieve a more modular and flexible product. }\end{array}$ \\
\hline Drew Vogel Xaraya 0.9.10 & FLOSS CMS with a good reputation and diffusion in Northern Europe \\
\hline eZ systems eZ Publish 3.x
\end{tabular}




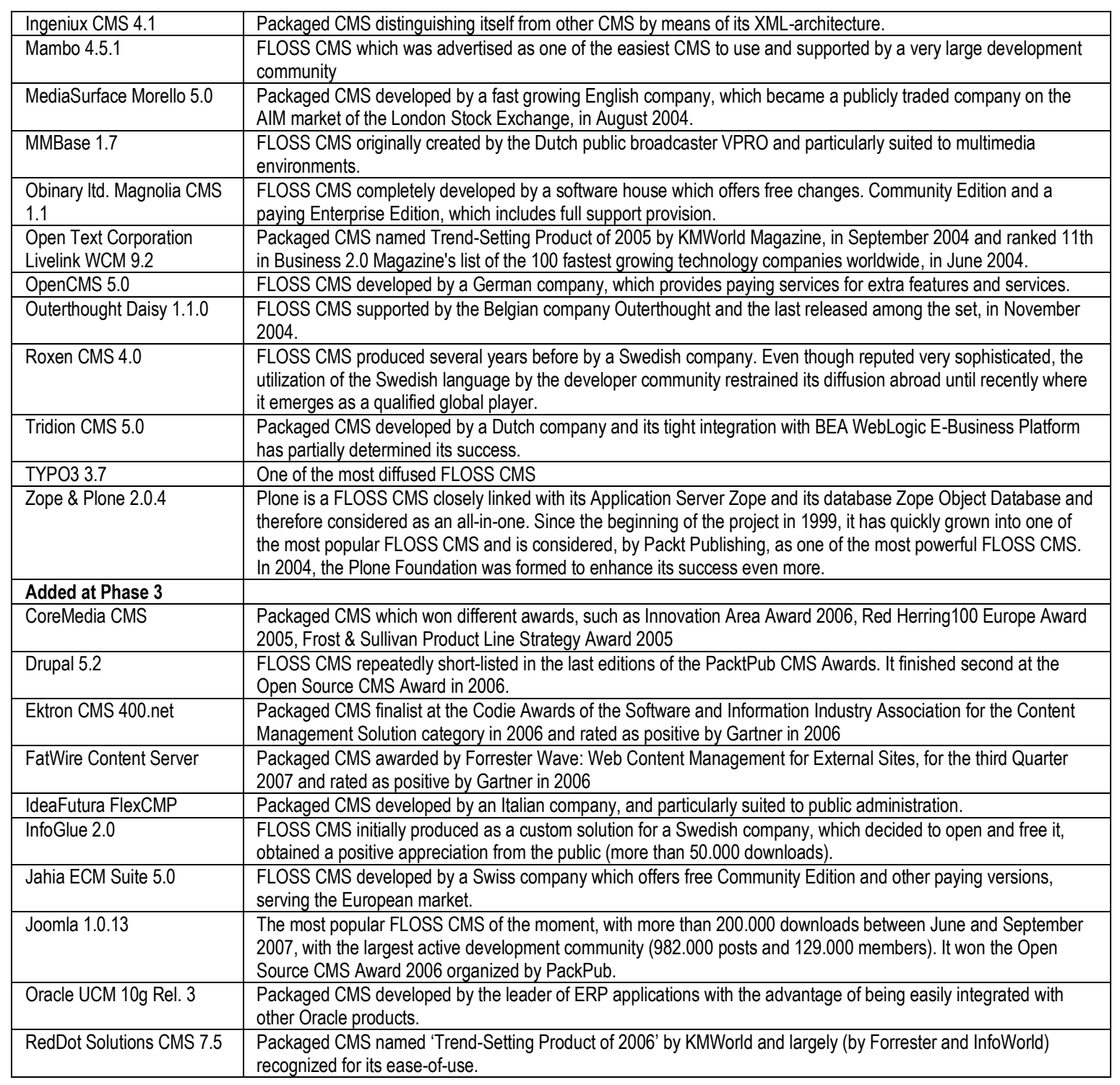

Table 5 The set of applications in Phase 1

\begin{tabular}{|c|c|c|c|c|c|c|c|c|c|c|}
\hline & \multicolumn{3}{|c|}{ Phase 1- 2002} & \multicolumn{3}{|c|}{ Phase 2 - 2004} & \multicolumn{4}{|c|}{ Phase 3 - 2007} \\
\hline CMS & Version & $\begin{array}{c}\text { Cost } \\
\text { category }\end{array}$ & $\begin{array}{l}\text { Func } \\
\text { tions }\end{array}$ & Version & $\begin{array}{c}\text { Cost } \\
\text { category }\end{array}$ & $\begin{array}{l}\text { Func } \\
\text { tions }\end{array}$ & Version & $\begin{array}{c}\text { Cost } \\
\text { category }\end{array}$ & $\begin{array}{l}\text { Func } \\
\text { tions }\end{array}$ & $\begin{array}{c}\text { Servi } \\
\text { ces }\end{array}$ \\
\hline Documentum & ECM 4i 4 & $\begin{array}{l}\text { middle } \\
\text { market }\end{array}$ & 26 & WCM 5.2 & enterprise & 95 & EMC 5.3 & $\begin{array}{l}\text { middle } \\
\text { market }\end{array}$ & 182 & 20 \\
\hline Interwoven & TeamSite 5 & $\begin{array}{l}\text { middle } \\
\text { market }\end{array}$ & 23 & $\begin{array}{l}\text { TeamSite } \\
6.0\end{array}$ & enterprise & 90 & $\begin{array}{l}\text { TeamSite } \\
6.7\end{array}$ & $\begin{array}{l}\text { middle } \\
\text { market }\end{array}$ & 171 & 19 \\
\hline Vignette & $\begin{array}{l}\text { Content } \\
\text { Suite } 6 \\
\end{array}$ & $\begin{array}{l}\text { middle } \\
\text { market }\end{array}$ & 15 & V7 & enterprise & 107 & Rel. 7 & $\begin{array}{l}\text { middle } \\
\text { market }\end{array}$ & 161 & 19 \\
\hline Microsoft & $\begin{array}{l}\text { CM Server } \\
2001\end{array}$ & $\begin{array}{l}\text { Lower } \\
\text { priced }\end{array}$ & 14 & $\begin{array}{l}\text { CM Server } \\
2002 \text { SP1 }\end{array}$ & upper tier & 74 & $\begin{array}{l}\text { SharePoint } \\
\text { Server } \\
2007\end{array}$ & $\begin{array}{l}\text { lower } \\
\text { priced }\end{array}$ & 162 & 20 \\
\hline Open Text Corporation & & & & $\begin{array}{l}\text { Livelink } \\
\text { WCM } 9.2\end{array}$ & enterprise & 106 & $\begin{array}{l}\text { Livelink } \\
\text { WCM } 9.7\end{array}$ & $\begin{array}{l}\text { lower } \\
\text { priced }\end{array}$ & 142 & 20 \\
\hline TYPO3 & & & & 3.7 & FLOSS & 84 & 4.1 & FLOSS & 176 & 17 \\
\hline Zope \& Plone & & & & 2.0 .4 & FLOSS & 77 & 3.0 & FLOSS & 181 & 18 \\
\hline MediaSurface & & & & Morello 5.0 & upper tier & 75 & Morello 5.5 & $\begin{array}{l}\text { middle } \\
\text { market }\end{array}$ & 158 & 17 \\
\hline OpenCMS & & & & 5.0 & FLOSS & 70 & 7.0 .1 & FLOSS & 120 & 15 \\
\hline eZ systems & & & & $\begin{array}{l}\text { eZ Publish } \\
3 . x\end{array}$ & FLOSS & 69 & $\begin{array}{l}\text { eZ Publish } \\
3.8\end{array}$ & FLOSS & 158 & 17 \\
\hline Tridion & & & & CMS 5.0 & upper tier & 66 & CMS 5.0 & $\begin{array}{l}\text { middle } \\
\text { market }\end{array}$ & 135 & 21 \\
\hline
\end{tabular}




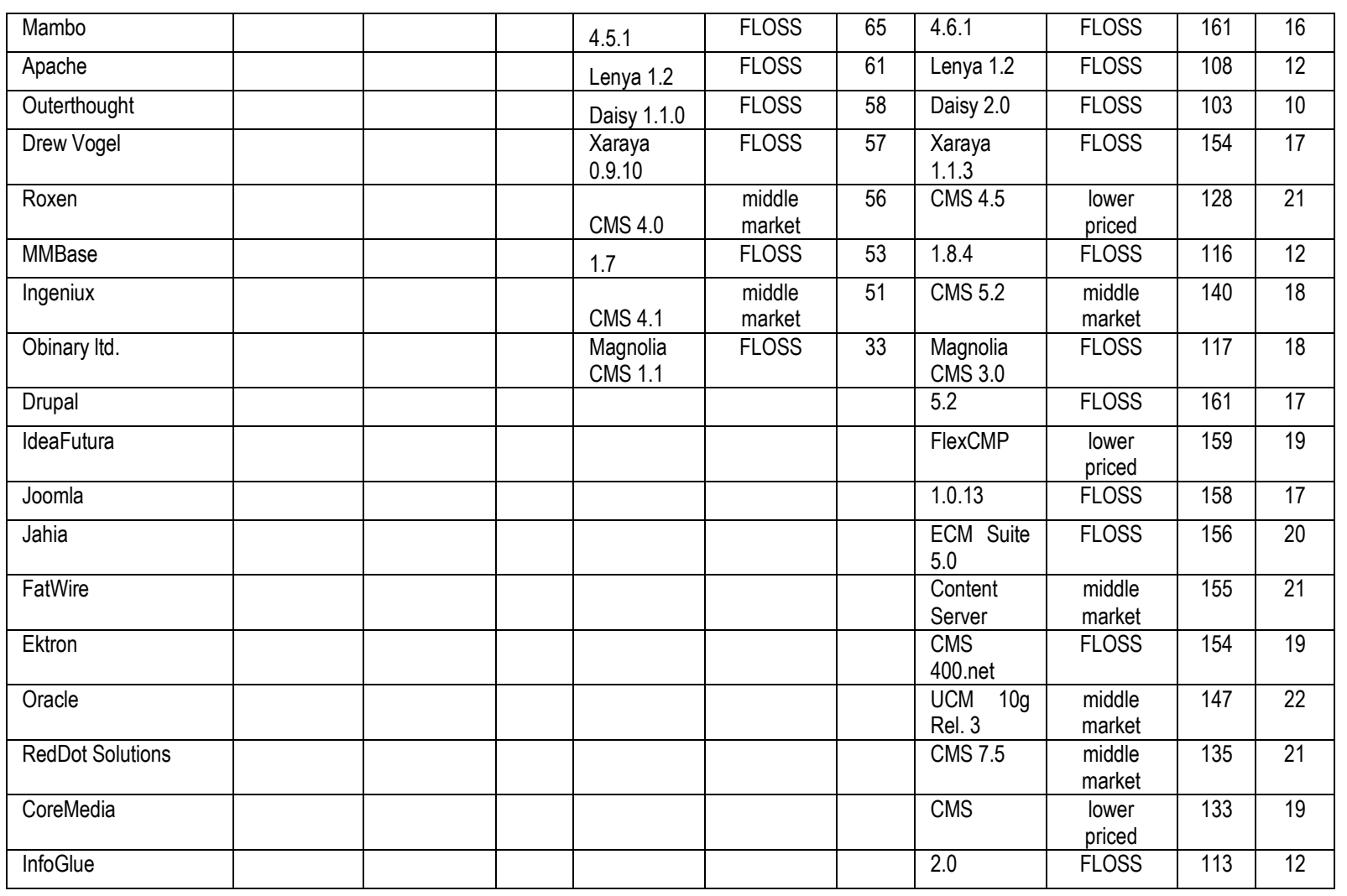

Table 6 The version, cost category, function and service (only in Phase 3 ) values across time

\section{Vitae}

Claudio Vitari is an assistant professor of Management Information Systems at Grenoble Ecole de Management. His published research includes articles in Communications of the Association for Information Systems, International Journal Knowledge Management, Journal of Information Technologies Cases and Applications. He has over 9 years' experience in teaching, research and consultancy and he obtained his PhD from Montpellier University and Carlo Cattaneo University.

Aurelio Ravarini is senior assistant professor of Information Systems at the School of Engineering at Università Carlo Cattaneo, where he is also Head of CETIC, Research Center on Information Systems. He also holds a Laurea in Engineering Management from Politecnico di Milano. He published more than 30 papers on international journals, book chapters or conferences proceedings and he serves as associate editor, editorial board member and program committee member in journals and conferences. 